\title{
Investigation of Residual Stresses in $\mathrm{ZrO}_{2}-\mathbf{2 0} \% \mathrm{MgO}$ Thermally Sprayed Coating Using X-Ray Diffraction Technique
}

\author{
Zainab H. Lafta ${ }^{1}$,Adel K. Mahmoud ${ }^{2}$, Ekhlas E. Kader ${ }^{3}$ \\ ${ }^{1,3}$ Department of Mechanical Engineering, College of Engineering-University of Diyala \\ ${ }^{2}$ Department of Materail Engineering, College of Engineering - University of Diyala \\ *corresponding author: email address: en,zainab4458@gmail.com
}

\begin{abstract}
The aim of this work is to investigates the residual stresses and microstructural characteristics of advanced composite ceramic coatings $\left(\mathrm{ZrO}_{2}-20 \% \mathrm{MgO}\right)$ which were produced by thermal spraying coating (flame spraying) onto the low carbon steel substrate (AISI 1015) steel. The bond coat used in this work was NiCrAlY alloy between metallic substrate and advanced composite ceramic coatings which was implemented by flame spraying technique. The residual stresses were evaluated by X-ray diffraction techniques using $\sin ^{2} \psi$ method.Microstructural examination studied by using scanning electron microscopy (SEM) and ( EDS) . The thickness of bond coating was $(260 \mathrm{Mm})$ and for composite ceramic coating was $(520 \mathrm{Mm})$. The results indicated that the residual stresses were compressive residual stresses. The
\end{abstract} magnitudes of the stresses in the as-sprayed condition are low and its value was (-19.041 MPa).

Keywords: X-ray; residual stresses $\mathrm{ZrO}_{2}-20 \% \mathrm{MgO}$; flame spray technique.

Paper History : Received:4-7-2019; Accepted:19-11-2019

\section{1-INTRODUCTION}

Residual stresses can be defined as those stresses that remain in a material or structure after manufacturing and processing in the absence of external forces or thermal gradients .Causes of residual Stresses may be manufacturing process such as , welding, machining, forming and heat treatments through thermal gradient .Residual stresses are known to play an important role in coating durability; for example, tensile residual stresses typically increase the susceptibility to cracking and deboning [1]. Residual stresses develop during cooling of a thermal spray coating due to the mismatch of thermal expansion coefficients of the coating and substrate. Depending on the relative magnitudes of the thermal expansion coefficients of the coating and substrate [2-3] residual stress can be either tensile or compressive Parameters that strongly affect the magnitude of residual stresses are coating and substrate temperature during spray deposition and properties of the coating such as thickness, roughness and porosity. Experiments have shown that residual stresses increase with coating thickness and deposition temperature [4]

Generally, the residual stresses of thermally sprayed coatings are induced by different mechanisms and sources
[5-7]. In a thermal spray process with a high flame temperature, such like flame spray, plasma spray, or arc spray, fully and partially molten particles striking onto the surface of the substrate, are flattened, solidified, and cooled down in a very short period of time (few microseconds)[8,9]. After their solidification and adhesion onto the surface of the substrate, the contraction of the splats can be hindered by substrate material or the underlying solidified coating material which results in tensile stresses which are called intrinsic, deposition, or quenching stresses. Due to an extremely high temperature difference, a high theoretical residual stress in the order of up to $1 \mathrm{GPa}$ can be induced. However, due to the many relaxation mechanisms, such as the sliding of the splats, micro cracks, plastic deformations, and material creep, the experimentally measured values are much lower $(<100$ $\mathrm{MPa}$ [10]. X-ray diffraction has used as a complementary technique; it can determine stress only in a thin surface layer [11]. Many researchers have determined the residual stresses of thermal spray coatings employing different techniques.

Santana et al., 2008 [12] Studied the residual stresses of coating by using of XRD and hole drilling methods .Highvelocity oxygen-fuel (HVOF) spraying has shown to be one the best methods for depositing WC-Co powders on plan Carbon steel substrate. It has been found that the mean residual Von Mises stress was higher in the thinner coating than in the thicker one, of approximately 180 and $107 \mathrm{MPa}$, respectively. Chen et al., 2015 [13] investigated the residual stresses in a NiCoCrAlY bond coat for thermal barrier coating on a Ni-based super alloy substrate by high velocity oxygen fuel spraying (HVOF) using X-ray diffraction. The stresses were found to be tensile of magnitude closed to $60 \mathrm{MPa}$. Zoei, Sadeghi and Salehi, 2016[14] studied the residual stresses of WC-10Co-4Cr coated by high velocity oxy fuel (HVOF) on the steel plates type AISI 1010. And evaluated them using X-Ray diffraction (XRD) technique. The results were found to be compressive residual stresses of $(210.3 \pm 75.1) \mathrm{MPa}$

Qu et al., 2018 [15] Investigated the high temperature residual stress in a typical Thermal barrier coatings (TBC), nanostructured $8 \mathrm{wt} \%$ yttria partially stabilized zirconia (YSZ) coating by in-situ high temperature indentation method. The residual stress was measured to be -131.3 , 55.5 and - 45.5 MPa, correspondingly. Moreover, the 
residual stresses decrease with increasing environmental temperature.

The objective of this work has to further explore the use of X-ray diffraction to determine the residual stresses in composite ceramic coating $\left(\mathrm{ZrO}_{2}-20 \% \mathrm{MgO}\right)$ sprayed on low carbon steel substrates, where this technique has high accuracy and it is nondestructive technique therefore used in the present study. And study the microstructure effect on the nature of residual stresses

\section{2-EXPERIMENTAL PROCEDURES}

AISI 1015 plain-carbon steel cylindrical substrates that's dimensions have $15 \mathrm{~mm}$ in diameter and $10 \mathrm{~mm}$ in height. The chemical composition is analyzed in Ministry of Industry and Minerals, state company for Inspection and Engineering Rehabilitation Baghdad shown in table(1). The surface roughness of the substrates was increased by using sand blast under pressure 8.5 bar and $40 \mathrm{~cm}$ of distance. The surface has then cleaned and degreased using acetone An average surface roughness of $5.48 \mu \mathrm{m}$. A commercial NiCrAlY was used as feedstock powder for the bond coat, whereas for the top coat $\left(\mathrm{ZrO}_{2}-20 \% \mathrm{MgO}\right)$ powders were selected. the powder mixture has ball milled for 2 hr with using speed of $(300$ r.p.m) to get homogenous particles

distribution. mechanical properties of material as shown in table 2 .

The powders were sprayed by flame sprayingsystem onto the substrates using an oxygen-acetylene gun. Show in the figure(1) The heat flame was produced by the burning of oxygen and acetylene, where the molten powder is carried out in the gas mixture and is attached to the surface to be coated by the high temperature of the torch which could raise to $3000 \mathrm{C}^{\mathrm{o}}$. It is required to control the pressure of the gases to obtain the flame equal to the speed of the powder rush. The oxygen pressure should be adjusted according to the spray gun used no more than 4 bar and the acetylene pressure not more than 0.7 bar before spraying process. The conditions of deposition process were listed in Table (3).

Table 1 Chemical Composition of plain-carbon steel (AISI 1015)substrate

\begin{tabular}{|c|c|c|c|c|c|c|c|c|c|c|c|}
\hline $\mathrm{C} \%$ & $\mathrm{Si} \%$ & Mn\% & P\% & $\mathbf{S} \%$ & $\mathrm{Cr} \%$ & Мо\% & $\mathrm{Ni \%}$ & Al\% & $\mathrm{v} \%$ & сu\% & $\mathrm{Fe} \%$ \\
\hline 0.138 & 0.19 & 0.538 & 0.0129 & 0.0156 & 0.0803 & 0.0154 & 0.0963 & 0.0069 & 0.0015 & 0.318 & Balance \\
\hline
\end{tabular}

Table 2 Mechanical properties of material

\begin{tabular}{|c|c|c|}
\hline material & Elastic modulus & Posion ratio \\
\hline AISI(1015) & $190-210 \mathrm{GPa}$ & $0.27-0.30$ \\
\hline $\mathrm{ZrO}_{2}$ & $100 \mathrm{GPa}$ & 0.22 \\
\hline $\mathrm{MgO}$ & $270 \mathrm{GPa}$ & 0.35 \\
\hline
\end{tabular}

Table 3 Operating parameters during thermal spraying coating technique

\begin{tabular}{|l|l|}
\hline Operating Parameters & Values \\
\hline Oxygen pressure (bar) & 4 \\
\hline Acetylene pressure( bar) & 0.7 \\
\hline Distance( cm) & 20 \\
\hline Powder feed rate $\left(\mathrm{cm}^{3} / \mathrm{min}\right)$ & 7 \\
\hline Particle size $(M \mathrm{~m})$ & $(100-300)$ \\
\hline & \\
\hline Temperature substrate $\left(\mathrm{C}^{\mathbf{o}}\right)$ & $(300-450)$ \\
\hline
\end{tabular}




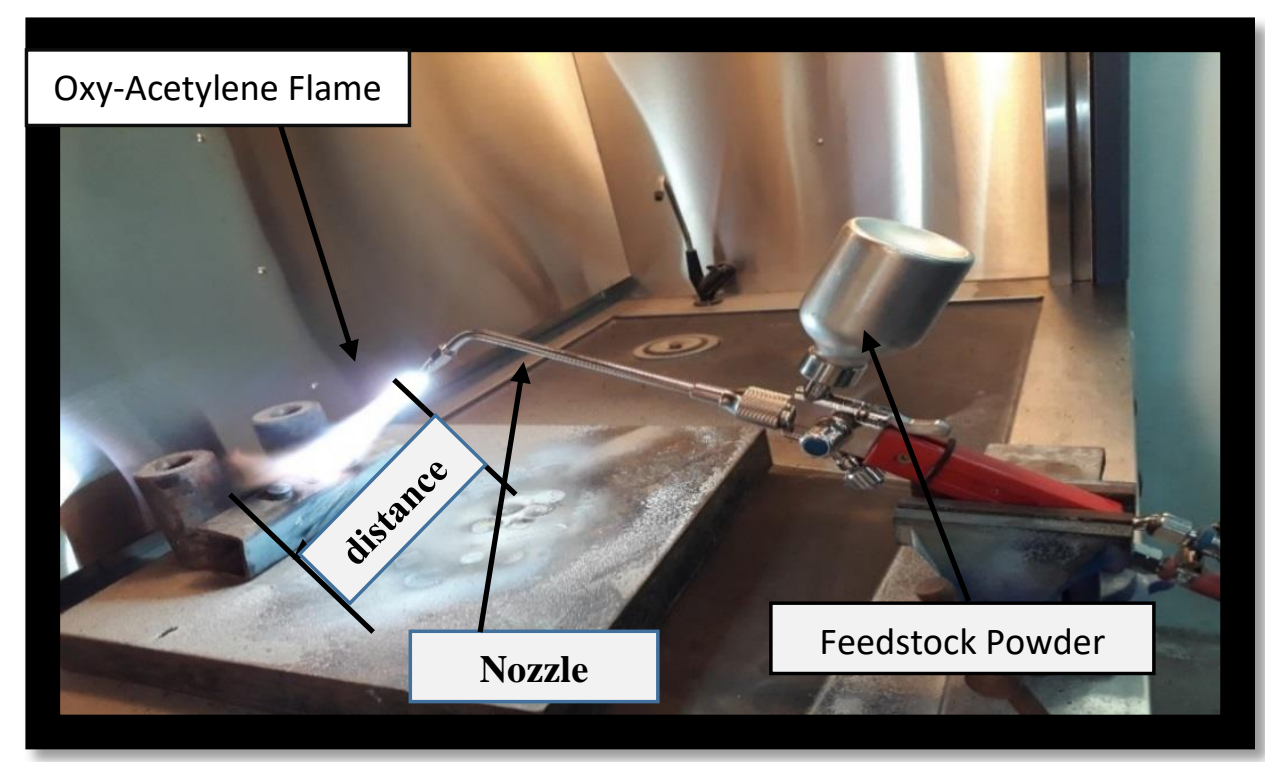

Figure 1: Flame spraying system

\section{3-RESIDUAL STRESS ANALYSIS}

XRD-based residual stress measurements were made using standard dspacing vs. $\sin 2 \psi$ techniques using Shimadzu X-Ray Diffractometer type XRD-6000 and $\mathrm{CrK} \alpha$ radiation as shown in figure (2). The $\sin 2 \psi$ method $[16,17]$ was used to determine the residual stresses in this work, the change of a lattice plane distance (d spacing) of a phase, i.e., the peak shift of the corresponding reflection, was measured for tilt $\psi$ angles between $0^{\circ}$ and $45^{\circ}$. To calculate the residual stresses the linear regression of the plot (d spacing) versus $\sin 2 \psi$ and the $\mathrm{X}$ - ray elastic constants. The coating and substrate physical properties (elastic modulus, Poisson's ratio, ) thickness of the top coating, might be calcalated. To calculate elastic modulus and Poisson's ratio for composite coatings using the following equations [18] .

$$
\begin{aligned}
& (1 / \mathrm{EC})=\left(w t_{1} \% / E_{1}\right)+\left(\mathrm{wt}_{2} \% / \mathrm{E}_{2}\right) \\
& v=\sum v * w \mathrm{t} \%
\end{aligned}
$$

The deposition temperature used in the present work during coating process for the topcoat and bond coat was $850 \mathrm{C}^{\circ}$.

From Shimadzu X-Ray Diffractometer XRD-6000 chart, will be getting on the following values are shown in the table 4 .

\begin{tabular}{|c|c|}
\hline 2Odegree & 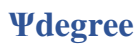 \\
\hline 156.231 & 0 \\
\hline 156.271 & 15 \\
\hline 156.271 & 30 \\
\hline 156.328 & 45 \\
\hline
\end{tabular}

Table 4. The relationship between $2 \mathrm{O} \& \psi$ for $\left(\mathrm{ZrO}_{2}+20 \% \mathrm{MgO}\right)$ coating

By Brag Law $(\mathrm{n} \lambda=2 \mathrm{~d} \sin \theta)$ may be calculated $(\mathrm{d})$, where $\mathrm{n}=1, \lambda=2.28970 \mathrm{~A}^{\circ}$ and $\Theta(0,15,30,45)$ degree. From the figure 3 may be calculated the linear slop of the plot dspacing versus $\sin 2 \psi$. The stress can then be obtained from the following equation:
$б=\left(\frac{E}{1+\vee}\right) * 1 / d o(\partial d /(\partial \backslash / \sin \rrbracket \wedge 2 d))$

From figure1 the slop $\partial \mathrm{d} /(\partial \llbracket \sin \rrbracket \wedge 2 \mathrm{~d}))=-0.00025$

$\mathrm{d}^{\mathrm{o}}=2.02712 \mathrm{~A}^{\mathrm{o}}$ 
from Eq. (3), the value of the Residual stresses is:

$\sigma=-19.0414 \mathrm{Mpa}$

Table 5.shows symbols of used in equation $(1,2,3)$

\begin{tabular}{|c|l|}
\hline$б$ & Residual stresses \\
\hline$E$ & young modulus \\
\hline$V$ & poison ratio \\
\hline$E_{c}$ & elastic modulus for composite \\
\hline
\end{tabular}
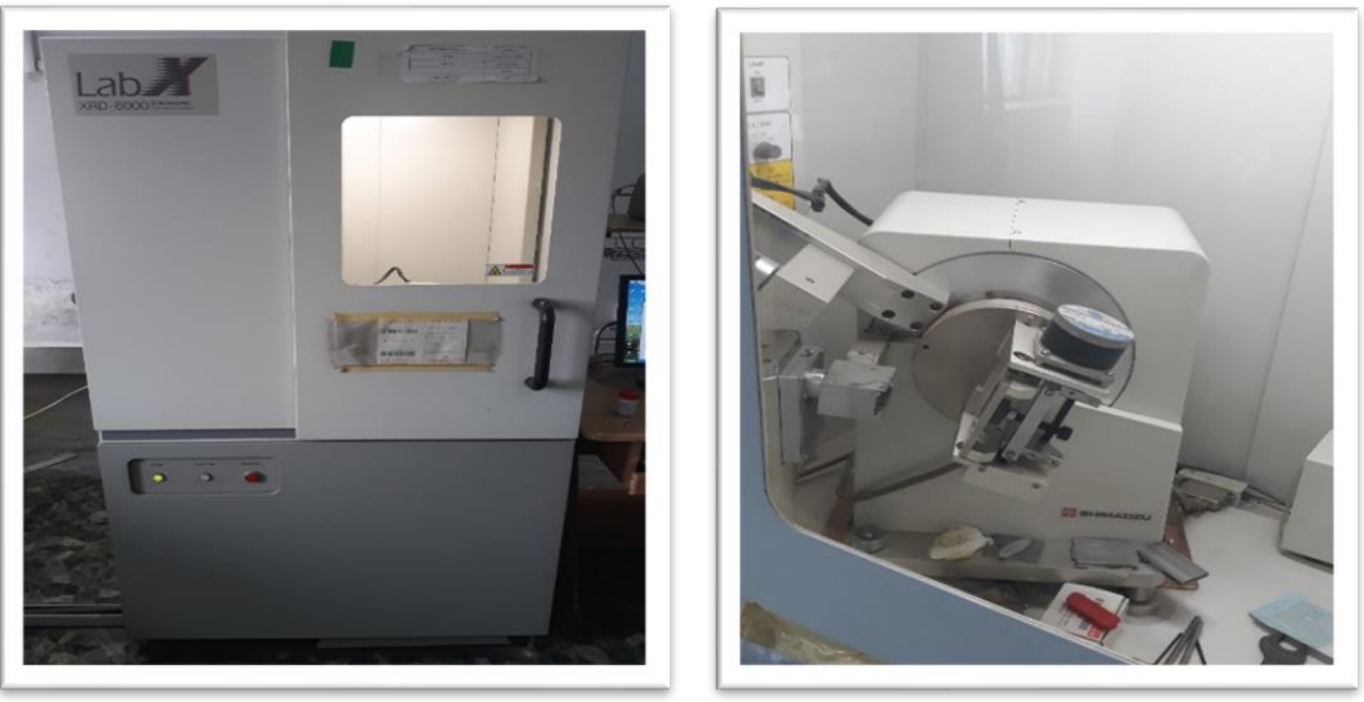

Figure 2: The X-Ray diffraction instrumentation.

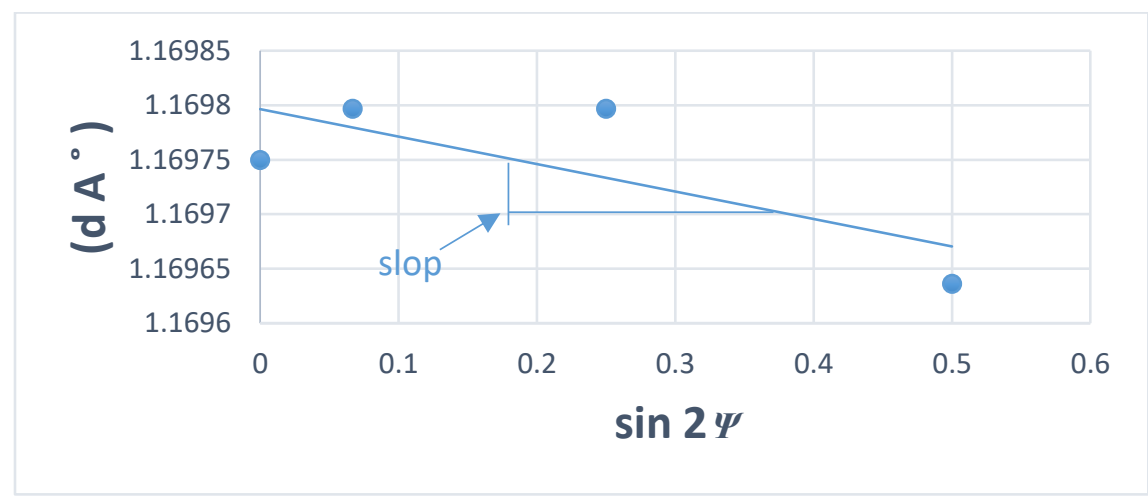

Figure 3: The relationship between $(\sin 2 \psi)$ and d-spacing $\left(\mathrm{A}^{\circ}\right)$ for $\left.\mathrm{ZrO}_{2}+20 \% \mathrm{MgO}\right)$ coating.

\section{4-REULTS AND DISCUSSION}

\section{4-1 Microstructure}

Figure (4) shows the surface of $\left(\mathrm{ZrO}_{2}-20 \% \mathrm{MgO}\right)$ coating .The surface showed typical microstructure of flame sprayed coating with open pores, lamellae boundaries and splats. A large number of fine particles have observed on the surface of ceramic coating because of some the coating particles that did not deform appreciably on impact. Sites can be distinguished where continuous, very fine porosity will be prevalent (formed by splat splashing causing the surface roughness and imperfect bonding between adjacent lamella). The lower percentage of the porosity give enhanced mechanical properties , and good quality of coating . 


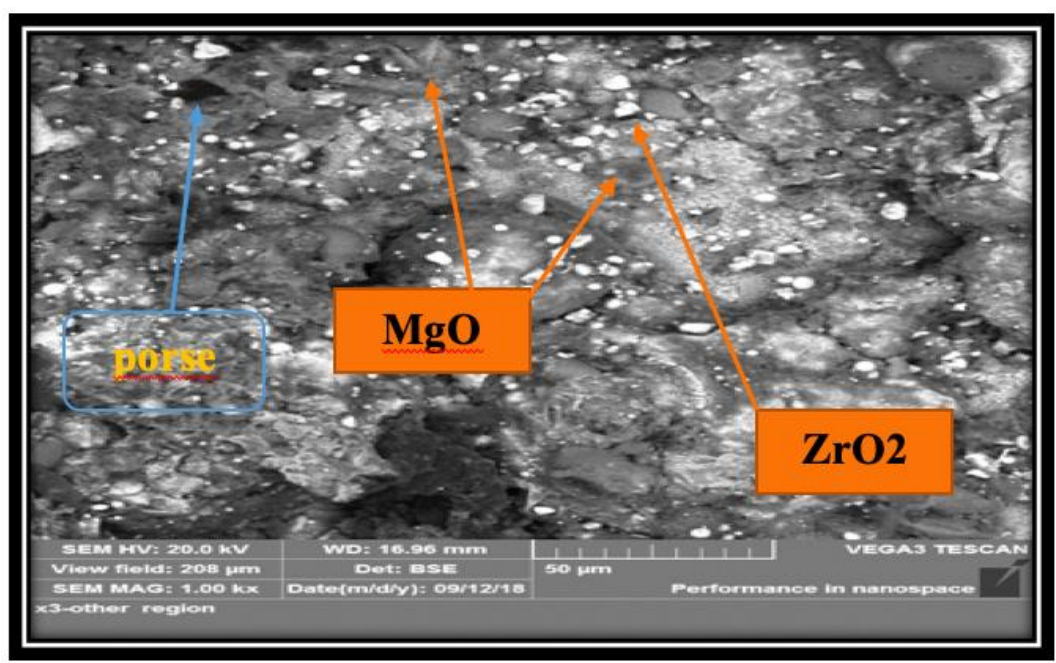

Fig. 4. Cross-sectional SEM images of $\left.\mathrm{ZrO}_{2}-20 \% \mathrm{MgO}\right)$

\subsection{Phase analysis}

The high-energy X-ray transmission technique allows for localized determination of the phase composition throughthe thickness of the top coat layer[19]. Shown in figure 5 , the phase composition is analyzed for the assprayed and heat-treated coatings. The $\left(\mathrm{ZrO}_{2}-20 \% \mathrm{MgO}\right)$ consisted of tetragonal and monoclinic zirconia phases of the coating layer, in addition cubic the magnesia phase., that have produced during coating process because there are different solidification and cooling rate to the composite ceramic coating mixtures during flame spraying process depend on the coating parameters resulted in different phases of coating layers. When increase cooling rate the retained phases increasing ,especially (tetragonal phase) for zirconia consequently, the quantity of compressive residual stresses increased resulted in enhancing in fracture toughness of composite ceramic coating

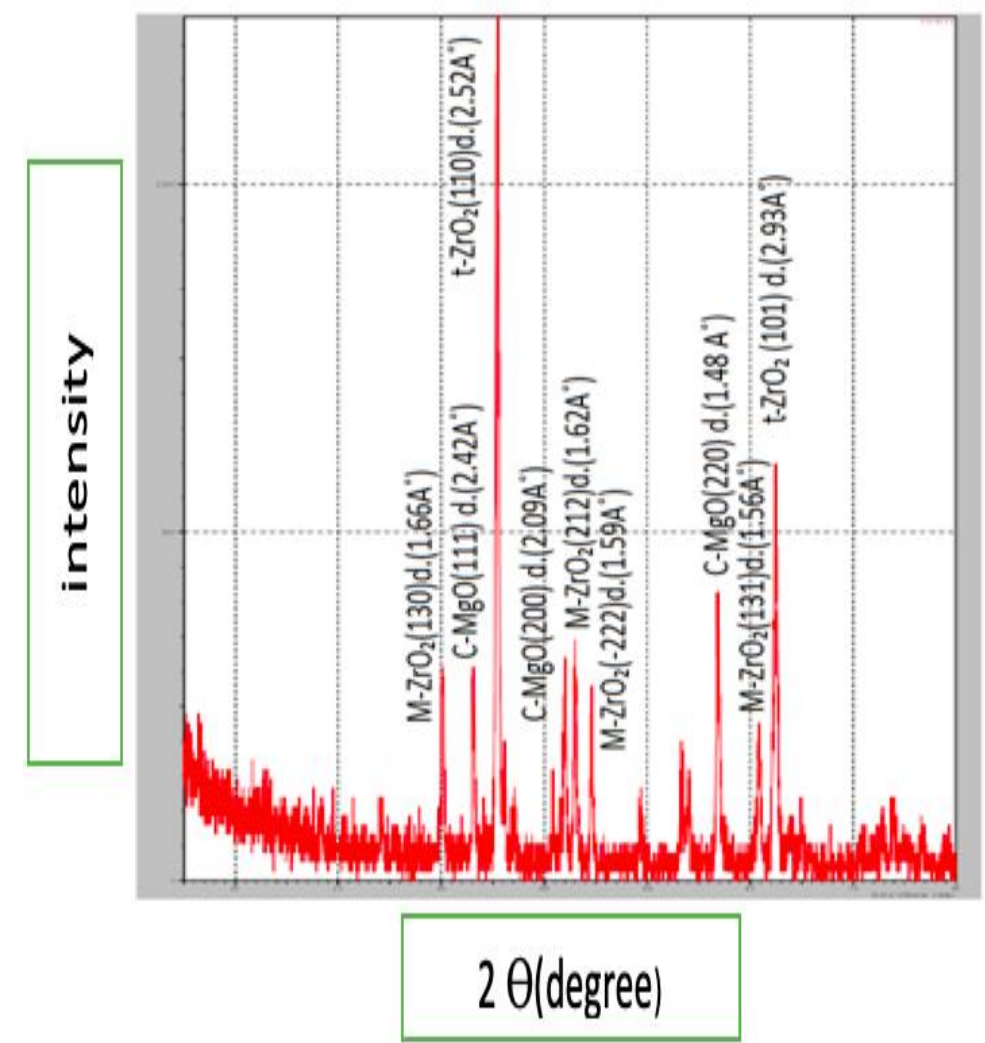

Fig. 5. XRD results of ( $\left.\mathrm{ZrO}_{2}-20 \% \mathrm{MgO}\right)$ as-sprayed coating 


\subsection{Residual stress measurement $-X R D$ results}

It can be referred from from $\mathrm{Eq}(3)$ that in topcoat $\left(\mathrm{ZrO}_{2}-20 \% \mathrm{MgO}\right)$ has subjected to compressive residual stresses (-19.0414 Mpa). This residual stresses have evaluated in the surface layer of coating adherent to the substrate. Thickness of topcoat layer conforming to the X-ray penetration has observed $450 \mu \mathrm{m}$. The study has carried out at several sites of each coating and the residual stresses have always determined along two perpendicular directions corresponding to tilt angles of $0^{\circ}, 15^{\circ}, 30^{\circ}, 45^{\circ}$. The results showed for each sample characteristics of a plane- equiaxial and compressive stress state, with constant values at sites far from the borders or

irregularities. The results presented in the remainder of the study confirm this feature. The level of the residual stresses in the topcoat surface has related to characteristics of composite ceramic coating $\left(\mathrm{ZrO}_{2}-\right.$ $20 \% \mathrm{MgO}$ ) deposited by flame spraying technique. The parameters considered were the substrate material (AISI 1015), the substrate thickness $(10 \mathrm{~mm})$, and a bond coat of NiCrAlY $(260 \mu \mathrm{m})$. As can be observed, the level of the residual stresses remains constant for all the samples inside the error bars. This behavior can be related to the stress relief by extensive micro-cracking during spraying. The coating flaws, porosities and microcracks have an important effect on the stress release and only quenchin stresses remain in the finished deposit.

\section{5-Conclusions}

The composite ceramic coating $\left(\left(\mathrm{ZrO}_{2}-20 \% \mathrm{MgO}\right)\right.$ has been produced successfully by thermal spraying coating (flame spraying technique), the microstructure of this coating showed that the coating layer open pores, lamellae boundaries and splats. The thickness of composite ceramic coating was $(520 \mathrm{Mm})$. The phases produced after coatings process were tetragonal and monoclinic structure for zirconia phases in addition to cubic for magnesia phase. The residual stresses evaluated using $\mathrm{X}$ - ray diffraction technique, which were the quality of these stresses were compression residual stresses and their value (-19.0414 Mpa) . the residual that compressive stresses are useful in advanced ceramic coatings, where, it contribute enhancement of the fracture toughness .

\section{References:}

[1].T.C. Totemeier, J.K. Wright " Residual stress determination in thermally sprayed coatings-a comparison of curvature models and X-ray techniques" Surface \& Coatings Technology 200 (2006) 3955 - 3962. [2].O. Kesler a, J. Matejicek b, S. Sampath b, S. Suresh a, T. Gnaeupel-Herold c, P.C. Brand c, H.J. Prask c" Measurement of residual stress in plasma-sprayed metallic, ceramic and composite coatings" Materials Science and Engineering A257 (1998) 215-224.
[3].Dietrich Mum, Matthias A. Sckuhr, and Yingyuan Yang" Thermal Stresses in Ceramic-Metal Joints with an interlayer" J, Am. Ceram. Soc., 78 [21 285-90 (1995)].

[4].R. Ghafouri-Azar, J. Mostaghimi, S. Chandra "Modeling development of residual stresses in thermal spray coatings" Computational Materials Science 35 (2006) 13-26.

[5].J. Stokes and L. Looney, Residual Stress in HVOF Thermally Sprayed Thick Deposits, Surf. Coat. Technol., 2004, 177-178, p 18-23.

[6]. L. Pawlowski, The Science and Engineering of Thermal Spray Coatings, Wiley, New York, 2008.

[7]. S. Sampath, X. Jiang, J. Matejicek, L. Prchlik, A. Kulkarni, and A. Vaidya, Role of Thermal Spray Processing Method on the Microstructure, Residual Stress and Properties of Coatings: An Integrated Study for Ni5wt \%Al Bond Coats, Mater. Sci. Eng. A, 2004, 364(1-2), p 216-231.

[8].Aqeel Ali Al-Attar, et al.'The effect of spin coating speed and deposition parameters on the crystalline size of $\mathrm{ZnO}$ thin films", Diyala Journal of Engineering Sciences, (2013), Vol.6, Issue 4, pp.100-106.

[9].Abdul Jabbar Saad Jumah. "Characterization corrosion behavior of nano alumina coatings on Al12Si fabricated by electrophoretic deposition", Diyala Journal of Engineering Sciences, (2014), Vol.7, Issue 4, pp.99114.

[10]. W. Luo, U. Selvadurai, and W. Tillmann Effect of Residual Stress on the Wear Resistance of Thermal Spray Coatings, Submitted April 1, 2015; in revised form September 2, 2015.

[11]. Olivera E. Kesler " Residual Stresses AndProperties of Layered and Graded Coatings" Doctor of Science in Materials Science, Massachusetts Institute of Technology 1999 .

[12]. Santana, Y. Y. et al. (2008) 'Characterization and residual stresses of WC-Co thermally sprayed coatings', Surface and Coatings Technology, 202(18) pp.45604565.doi:10.1016/j.surfcoat.2008.04.042.

[13]. Chen, Y. et al. (2015) 'Characterization and understanding of residual stresses in a NiCoCrAlY bond coat for thermal barrier coating application', . Acta Materialia Inc., 94, pp. 1-14. doi: 10.1016/j.actamat.2015.04.053.

[14]. Zoei, M. S., Sadeghi, M. H. and Salehi, M. (2016) 'Effect of grinding parameters on the wear resistance and residual stress of $\mathrm{HVOF}-$ deposited $\mathrm{WC}-10 \mathrm{Co}-4 \mathrm{Cr}$ coating', Surface and Coatings Technology. Elsevier B.V., 307, pp. 886-891. doi: 10.1016/j.surfcoat.2016.09.067.

[15]. Qu, Z. et al. (2018) 'High temperature fracture toughness and residual stress in thermal barrier coatings 
evaluated by an in-situ indentation method', Ceramics International. Elsevier Ltd and Techna Group S.r.1., 44(7), pp. 7926-7929.doi: 10.1016/j.ceramint.2018.01.230.

[16]. M.E. Fitzpatrick, A.T. Fry, P. Holdway, F.A. Kandil, J. Shackleton and L. Suominen, Determination of Residual Stresses by X-ray Diffraction - Issue 2, National Physical Laboratory Teddington, Middlesex, United Kingdom, TW11 0LW, September 2005.

[17]. J. Pina, A. Dias, J.L. Lebrun, Study by X- ray diffraction and mechanical analysis of the residual stress generation during thermal spraying, Materials Science and Engineering A347 (2003) 21/31.

[18]. Fitzpatrick, M. E., Fry, A. T., Holdway, P.,Kandil, F. A. and Shackleton, J., \& Suominen, L. (2005) 'Determination of residual stresses by X-ray diffraction. [19]. Weyant, C. M., Almer, J., \& Faber, K. T., Through-thickness determination of phase composition and residual stresses in thermal barrier coatings using high-energy X-rays. Acta Materialia,58(3),943-951. https://doi.org/10.1016/j.actamat.2009. 